\title{
$\bullet$ Stakeholders' Perspective Towards the Contingency Education Model During Covid 19 Pandemic
}

\section{IJCRR}

Section: Healthcare

Sci. Journal Impact

Factor: 6.1 (2018)

ICV: 90.90 (2018)

\section{Deepti Sharma, Deepshikha Aggarwal, Archana B. Saxena}

Department of Information Technology, Jagan Institute of Management Studies, Delhi, India.

(ब) (1) (8)

Copyright@IJCRR

\section{ABSTRACT}

Introduction: Covid-19 pandemic has an impact on worldwide education system. To avert the danger of human life, all school, colleges and university around the world have to be shut down. To circumvent the educational loss due to this pandemic, the educational bodies have decided to continue the teaching through online modes where instructor and students will be connected virtually.

Objective: This new model is considered as Contingency Educational Model (CEM). There are three major stakeholders in this Model: Students, Teachers and Parents. This paper is an effort to analyse the perspective of these stakeholders about this CEM. The scope of the paper is limited to the school and colleges of India Region.

Methods: To evaluate the above-mentioned aspect, the questionnaire method of survey was adopted by the authors. A questionnaire was designed keeping in mind IES (Indian Education system) and CEM (Contingency Education Model). Some of the key factors that authors considered are the usefulness of this model, skill enhancement of users, ease of use, privacy \& security, and intention to use this model.

Results: Based on responses given by the respondents, these aspects are evaluated, using MS Excel \& SPSS tools. The current paper has summarized the experiences of various stakeholders in the Contingency Education Model that has implemented on the recommendations of UNESCO.

Conclusion: The CEM is very much required to save the education loss that Covid-19 might generate due to all over world lockdown.

Key Words: CEM (Contingency Education Model), TAM (Technology Adoption Model), Covid 19, Corona Educational Impact, word cloud, Online teaching tools and methodology

\section{INTRODUCTION}

The current scenario of universal lockdown is the first of its kind in human history. COVID 19 has an impact on all the essential sectors of our lives. This pandemic has forced us in a situation where everything else around the life has to be shut down to protect life. To sync with the title of the paper, authors are going to discuss the impact of this contagion on the education system and its stakeholders. ${ }^{1}$ All over the world countries have rightly decided to protect the future generation from this crisis and closed all the schools, college and universities as the first step. ${ }^{2}$ The worldwide lockdown has an impact on around 1.725 billion learners around the world. $98.5 \%$ of the student population is bearing the educational losses as 158 countries are implementing nationwide closure and 35 are implementing local closures. ${ }^{3}$ Now the dilemma is with the policymakers they cannot open the educational institutes and simultaneously they don't want students to compromise on their studies. Countries very well realised that loss on education will not impact just the student, school or parents but it will lead to far-reaching economical and societal consequences. To strike a balance between these two teachings has been moved online by using some means. Even UNESCO (United Nations Educational, Scientific and Cultural Organization) has recommended continuing distance education or open education through virtual classroom. ${ }^{4}$ Authors will address this new model of education as CEM (Contingency Education Model) throughout the execution of this research piece. A CEM (Contingency Education Model) connects Students and teachers latitudes to continue

\section{Corresponding Author:}

Deepti Sharma, Department of Information Technology, Jagan Institute of Management Studies, Delhi, India. Email: deeptisharma@jimsindia.org.

ISSN: 2231-2196 (Print) ISSN: 0975-5241 (Online)

Received: 29.07 .2020

Revised: 02.10 .2020

Accepted: 29.10 .2020

Published: 05.01 .2021 
studies through virtual class rooms. ${ }^{5}$ The most important requirement of this online teaching availability of internet connects and a device that connects with the internet connection. With the help of internet connection and devices these virtual classrooms can be practised through various synchronous tools like; Google Meet, Zoom Meetings, MS Teams or asynchronous tools like sending videos through Whatsapp, tv channels, youtube videos. ${ }^{6,7}$ Unlike CEM, TEM (Traditional Educational Model) connect students and teachers through a physical environment (school) where educational subjects are completed along with physical and extra-curricular activities. Although it is correct that CEM has supported education system a lot during this pandemic but before making any conclusion it is important what various stakeholders have to say about this Educational model.

\section{DIFFERENT TOOLS/ MODES USED FOR TEACHING IN CEM}

To continue teaching during coronavirus outbreak, many schools and colleges have shifted their classroom teaching to online education. During social distancing and 'stay at home' order, online education is the need of the hour. Although elearning has been a catchword from last 4-5 years, covid-19 has forced the educational system to take thoughtful steps ahead $^{8}$. Starting from schools and colleges to different universities like Harvard, Stanford started offering their online courses free to the students. Academic resources are being shared by the number of schools, colleges and universities via online platforms and apps. Some use apps like Microsoft Teams, Google Meet and Zoom as virtual classrooms, while others are using WebEx, Moodle, Google Classrooms, Instructables. ${ }^{9}$ There are online platforms also which are offering online courses e.g., National Programme on Technology Enhanced Learning (NPTEL), Study Webs of Active-Learning for Young Aspiring Minds (SWAYAM), Meritnation, Topper, Extramarks etc. ${ }^{10,11}$ Instead, any educator can also use personalized tools and techniques according to their teaching methodologies. Recording lectures using camera and then circulating it among students via email groups, Whatsapp, telegram app, video conferencing platforms and also teaching webs are in use. ${ }^{12}$

There is several educational websites and online platforms which are offering help to students with their courses..$^{13}$ These websites have an advantage that student can learn at his own pace. BYJU's is one example of such a website where students can learn online from anywhere and anytime. BYJU's offers various subjects learning programs in English and Hindi for students..$^{14}$ Meritnation also offer classes in a wide range of subjects including science, mathematics, English, social studies, Hindi and General Knowledge. It makes each session interactive with the help of videos, quizzes and many more. It also offers 1 and 2 years online preparatory courses for NEET and IIT-JEE. The topper is another informative platform for students from classes 5 to 12 across national and state boards. ${ }^{15}$ Students can attend live classes, online classes and mock tests using this platform. Extramarks is a learning platform through which school-going as well as graduate entrance exam students' can work. Students can practice through different worksheets and can attend live classes for all subjects also.

Besides various online platforms, there are numerous apps also that help students to learn, attend and practice online. Google classroom is one such app for educators that help teachers to stay organized and track progress through their lesson plans. Instructables provide a platform to teachers through Do It Yourself (DIY) projects that can be included in lesson plans. This helps to reduce lesson planning significantly. ${ }^{16}$ Using Educreations app, teachers can create videos as part of lesson plans and assignments. At times, it is difficult to teach only through speaking, and this video and diagrams can help students to learn things quickly. Edmodo is designed with online teachers in mind; the app helps with digital organization of student work and lessons. Teachers can assign work, manage progress, and discuss feedback with students one on one and with parents/guardians too. Kahoot has given an excellent platform to students in the form of interactive games. Students can work towards completing game tasks and learn at the same time. Slack is a team communication tool that can be used for teacher-to-teacher, teacher-to-student, and even student-to-student messaging. TeacherKit is designed specifically for teachers that help them to track grades, attendance, and other factors. ${ }^{17}$

\section{FACTORS CONSIDERED IN CEM}

There are three major stakeholders in the Contingency Education Model (CEM). They are student, teacher and parent. The questions are designed keeping in view the concerns of all stakeholders. Some of the key factors that authors considered are the usefulness of this model, skill enhancement of users, ease of use, privacy \& security, and intention to use this model, privacy \& security, infrastructure support and impact on health. The questions and its description are given below in table 1 . This table describes the key factors considered in Contingency model. These factors are various questions which were asked to stakeholders through the questionnaire.

\section{Table 1: Key Factors Considered in CEM}

The stakeholders were analysed based on the following parameters concerning the online learning platforms.

Do the stakeholders feel that using Online learning platforms for learning and teaching saves their travel time. 
Do the stakeholders feel that using Online learning platforms for learning and teaching enables teaching and learning from far off places and sources.

Does use the Online learning platforms for learning and teaching is particularly useful at the times such as a pandemic when people have to stay at home.

Do the stakeholders feel that learning to use the Online learning platforms is easy.

Do the stakeholders feel that searching courses and content of choice is easy with the Online learning platforms.

Do the stakeholders feel that it is easier to learn and teach using the Online learning platforms rather than traditional teaching methods.

Do the stakeholders feel that using Online learning platforms for learning and teaching gives them access to tremendous learning resources which is not possible offline.

Do the stakeholders feel that Online learning platforms make assessment and evaluation easier.

Do the stakeholders feel that transition from traditional learning/ teaching to online learning/ teaching is easy.

Do the stakeholders feel that people having good technical skills have a better learning and teaching experience on Online learning platforms

Do the stakeholders feel that the online learning platforms prevent student teacher bonding.

Do the stakeholders feel that online learning platforms enable introvert students to be more participative in class.

Do the stakeholders feel that having a good internet connection is most important to use online learning platforms

Do the stakeholders feel that using online learning platforms leads to a sedentary lifestyle and is harmful to the health of the users.

Do the stakeholders feel that using online learning platforms leads to long exposure to electronic devices and is harmful to the eyes.

\section{MATERIALS AND METHDOS}

A primary survey is done to collect the data. A questionnaire based on the questions shown in table 1 is used. The questionnaire was sent through e-mail, Facebook or WhatsApp to around 250 people. Out of those, 172 people responded. All the responses were recorded for analysis purpose. Later, all the incomplete questions from the data collected have been cleaned and information is processed using Microsoft Excel analysis.

\section{Analysis of Data}

After collecting the data, the data is analysed and the results are shown in below tables. Table 2 and Figure 1 shows the number of students, parents and teachers participated in the survey. The total number of students who participated in the survey was $46.35 \%$, whereas parents were 33.11 and teachers were $7.2 \%$ only. The total contribution of both teachers and parents recorded was $13.2 \%$.

\section{Table 2: Stakeholder's Participation}

\begin{tabular}{lc} 
Stakeholder & Percentage \\
Students & 46.35761589 \\
Parents & 33.11258278 \\
Teachers & 7.284768212 \\
Both Teacher and Parent & $\mathbf{1 3 . 2 4 5 0 3 3 1 1}$ \\
\hline
\end{tabular}

Table 1 explains the participation made by different stakeholders like students, parents, teachers and both teacher and parent. Various stakeholders used to use the online learning platform before this pandemic situation also while others have started it only after the lockdown during online education. The interpretation is shown in table 3 which states the usage of online learning platform before and after lockdown.

\section{Table 3: Usage Pre/Post Lockdown}

$\begin{array}{lc}\text { Usage before Lockdown } & \text { Percentage } \\ \text { Yes } & 0.513333 \\ \text { No } & 0.483444\end{array}$

Table 3 investigate the usage of online learning platforms by different stakeholders' pre and post lockdown. It explains $51 \%$ of stakeholders agreed that they were using the online learning platform before lockdown also and $48 \%$ said that they started using it only after lockdown.

\section{RESULTS}

\section{Perception of stakeholders based on various factors}

Out of 172 respondents, stakeholders have provided their views based on various factors. The data was collected on a Likert scale of 1-5. Authors have eliminated the responses with values 1 to 3 for better results. The responses with value more than or equal to 4 are considered and shown in the form of percentage in Table 4. This table explains the stakeholder's perception based on different factors. Factors are related to travel time, lifestyle, internet connection, health factors, teacher bonding, safety and usefulness are explained in table 4. 
Table 4: Stakeholder's Perception based on Different Factors

\begin{tabular}{|c|c|c|c|}
\hline Factor & Student & Parent & Teacher \\
\hline Saves travel time & $79 \%$ & $63 \%$ & $77 \%$ \\
\hline Searching easy & $66 \%$ & $57 \%$ & $74 \%$ \\
\hline $\begin{array}{l}\text { Good technical skills lead to } \\
\text { better experience }\end{array}$ & $66 \%$ & $61 \%$ & $68 \%$ \\
\hline $\begin{array}{l}\text { Good technical skills make it } \\
\text { easy to search learning content } \\
\text { online }\end{array}$ & $66 \%$ & $70 \%$ & $74 \%$ \\
\hline Leads to sedentary lifestyle & $65 \%$ & $78 \%$ & $82 \%$ \\
\hline $\begin{array}{l}\text { Having a good internet con- } \\
\text { nection is most important }\end{array}$ & $90 \%$ & $96 \%$ & $97 \%$ \\
\hline $\begin{array}{l}\text { Long exposure to electronic } \\
\text { devices harmful for the eyes }\end{array}$ & $80 \%$ & $93 \%$ & $94 \%$ \\
\hline $\begin{array}{l}\text { Prevent student teacher bond- } \\
\text { ing }\end{array}$ & $70 \%$ & $74 \%$ & $68 \%$ \\
\hline $\begin{array}{l}\text { Good technical skills enable } \\
\text { us to keep data and personal } \\
\text { information safer online }\end{array}$ & $69 \%$ & $76 \%$ & $80 \%$ \\
\hline $\begin{array}{l}\text { Only useful at the times such } \\
\text { as a pandemic }\end{array}$ & $56 \%$ & $65 \%$ & $51 \%$ \\
\hline $\begin{array}{l}\text { Access to learning resources } \\
\text { and tools }\end{array}$ & $56 \%$ & $57 \%$ & $69 \%$ \\
\hline
\end{tabular}

Table 4 above describes the stakeholder's perception based on different factors like safety, usefulness, health issues, travelling time, the requirement of technical skills etc of online teaching. The observations of the respondents about these factors are described in section 4.3.

\section{Observations of the respondents about online teaching}

In the survey done by authors, the general feedback about their experience in online teaching and learning was also taken. Few respondents have posted positive effects while a few others shared negative aspects of online teaching. Some people told that online teaching enhances learning during the lockdown, interaction with teachers are better than the traditional model, safe and the interpersonal skills are improved whereas other say they are harmful to their children and offline mode is better. These views are represented in the form of a word cloud which is prepared using " $R$ " software. The following figure shows the word cloud for the general observations of the respondents in online teaching.

Figure 1 shows the word cloud for the general observations of the respondents in online teaching. It observes keywords and the feedback given by different stakeholders through the questionnaire given to them. Few have highlighted keywords like online education, interaction with teachers and interpersonal skills. Others pointed out that they are satisfied with this teaching methodology. Other highlighted words are fu- ture skills, exposure, traditional, harmful, benefits, solution and many more.

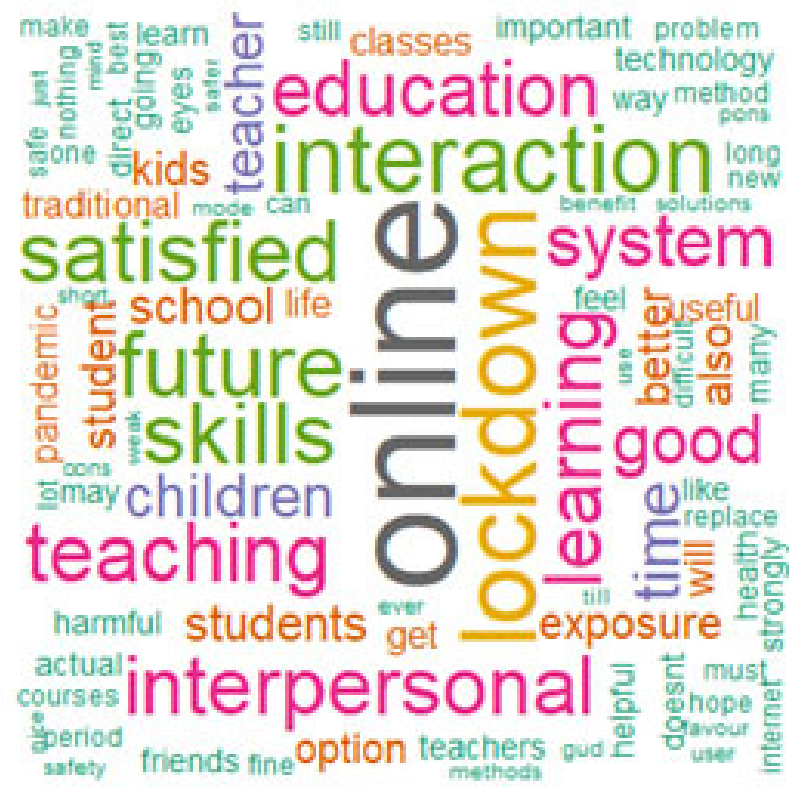

Figure 1: Word cloud for the general observations of the respondents in online teaching.

\section{CONCLUSION}

The current paper has summarized the experiences of various stakeholders in the Contingency Education Model that has implemented on the recommendations of UNESCO. The CEM is very much required to save the education loss that Covid-19 might generate due to all over world lockdown. The correct analysis of this paper will help us in bringing the improved version of CEM. In the improved version recommendations made by stakeholders can be included as improvement points and difficulties used by these benefactors can be tried to illuminate in the next version. With these improvements, we can adopt CEM as NEM (Normal Education Model) as online teaching is the future of classroom teaching or they both can go hand in hand.

\section{ACKNOWLEDGEMENT}

Authors acknowledge the immense help received from the scholars whose articles are cited and included in references to this manuscript. The authors are also grateful to authors/ editors/publishers of all those articles, journals and books from where the literature for this article has been reviewed and discussed.

\section{Conflict of Interest: NIL}

Source of funding: NIL 


\section{REFERENCES}

1. World Bank Education and Covid-19. https://www.worldbank. org/en/data/interactive/2020/03/24/world-bank-education-andcovid-19. Accessed on April 30, 2020.

2. Kasrekar DI, Wadhavane G. Impact of COVID-19 on Education system of India. Retrieved June 2020. www.latestlaws.com.

3. Impact of Covid-19 on Education System in India, https://www. latestlaws.com/articles/impact-of-covid-19-on-education-system-in-india/, Accessed in April 2020

4. Excel analysis tool pack, Retrieved June 2020, from https:// www.excel-easy.com: https://www.excel-easy.com/data-analysis/analysis-Jan, 2020

5. Covid-19 in India: Using digital Media in Teaching, Retrieved June 2020, from https://www.brookings.edu: https://www. brookings.edu/blog/education-plus-development/2020/05/14/ covid-19-in-india-education-disrupted-and-lessons-learned/, April 2020.

6. Education Mission Ahead, Retrieved 2020, from https://edition. cnn.com: https:/edition.cnn.com/2020/04/08/tech/online-education-india-coronavirus-spc/index.html, 2020.

7. Online classes during Lockdown from https://www.karnataka. com: https://www.karnataka.com/education/online-classesduring-lockdown/, accessed on . (2020, March). Retrieved June 2020

8. UNESCO's support:Education Response to COVID-19, from www.en.unesco.org: https://en.unesco.org/covid19/educationresponse/support accessed on. (2020, March). Retrieved June 2020
9. Ahmet Berk Ustun MW, An effective way of designing blended learning: A three phase design-based research approach. Edu Info Tech. 2020;25:1529-1552.

10. Aljawarneh SA, Reviewing and exploring innovative ubiquitous learning tools in higher education. J Comp Higher Edu 2019;32(4).

11. Best app for teachers. (n.d.). Retrieved from https://www.digitaltrends.com/mobile/best-apps-for-teachers-education/, Accessed in May 2020.

12. Best apps . (n.d.). Retrieved from http://anomalouseducator. com/best-apps-for-online-teachers/, accessed in May 2020.

13. COVID-19, Retrieved from https://www.worldbank.org: https:// www.worldbank.org/en/data/interactive/2020/03/24/worldbank-education-and-covid-19, April, 2020.

14. Online classes. (n.d.). Retrieved from https://www.karnataka. com/education/online-classes-during-lockdown/.

15. Shu-Chen YL. Learning online, offline, and in-between: comparing student academic outcomes and course satisfaction in face-to-face, online, and blended teaching modalities. Edu Info Tech 2018; 23(2):1-13.

16. Tools used by educators. (n.d.). Retrieved from https://www.redbytes.in/best-apps-for-teachers-and-educators/ accessed in May 2020.

17. Shinde SP, Deshmukh VP, Sawant BS. Web-based education in schools: a changing scenario of educational technology in India. Int J Curr Res Rev 2012;4(4):135-140. 